\title{
RETHINKING WORKER-CONSCIOUSNESS: Work, Class and Culture
}

\author{
Jimi O. Adesina
}

\begin{abstract}
This paper re-examines current thinking on worker-consciousness, and criticizes the prevailing reluctance to accommodate non-class identities in class subjectivity. Much of the problem with the discussion of worker-consciousness, the paper argues, is epistemological. Consciousness is both experiential and defined by 'preconstituted' knowledge. It is contradictory as much as it is a contested terrain of individual and group engagement with 'reality ${ }^{1}$. The experience of work, and class, is mediated by non-work and non-class experiences and identities, otherwise we miss the territoriality of class. Understanding workers as producers of knowledge allows an appreciation of how language, is itself, constitutive of identity and consciousness.
\end{abstract}

\section{INTRODUCTION}

Worker consciousness remains one of the more enigmatic aspects of the study of work and of the working class. Many of those writings in Marxian tradition treat workerconsciousness in an eclectic manner or avoid it altogether. In spite of the major advances of the labour process debate, initiated by Harry Braverman's seminal work, Labour and Monopoly Capital (1974), the issue of worker-consciousness remains one of the least studied aspects of the experience of work and class in that debate. Braverman's stated avoidance of worker-subjectivity was one of the few, though potent, weaknesses of his work. While most participants in the debate were stridently post-Braverman and sought to correct the 'errors' in his work, the treatment of worker-consciousness remained ad-hoc and eclectic. Burawoy's seminal work was itself caught in the Marcuse- structuralist pessimism. Worker-subjectivity was treated as a result of how the organization of work promotes workers' 
consent to their exploitation and domination (Burawoy, 1979). The works that prefigure the discourse on consciousness often treated worker-subjectivity in isolation from non-work experiences; the relative autonomy of the workplace.

Orthodox sociological discourse on worker-subjectivity is torn between functionalism and actionalism of the phenomenological variant. The structural-functionalists often dismiss the power of active human subjectivity, while the phenomenologists deny human-subject as a product of history or society. In the famous phenomenological-actionalist investigation of work experience and worker-subjectivity, work orientation was seen largely as imported into the workplace ( $c f$. Goldthorpe et al, 1968).

Much of orthodox Marxist discourses on (worker-consciousness), has been defined by stipulating the ideal-type working class consciousness. This consciousness is characterized by revolutionary uprising, the construction of socialism, and untainted by trade union pecuniary demands, nationalism, race, ethnic (and gender, perhaps), or other pollutants of class objective, qua class. Lenin's distinction between trade union and proletarian consciousness is reproduced in diverse ways. Two examples are Eric Hobsbawm's (1984) idea of 'no dassness' and Hudon's (1989) critique of Harold Wolpe, on the limits of national liberation option in the South African labour movement. In Hobsbawm's idea of 'nodassness', the language of class that is not specifically proletarian or is 'polluted' by precapitalist identities is discarded.

This paper engages more with the radical labour process and the more general Marxist-oriented discourse on worker-consciousness than with conventional sociology of work. The failure to confront the issue of worker-consciousness may itself reflect what was seen as the hegemonic domination of the working class, in the larger Marxist-oriented analysis. Hence, the impression that the issues the labour movements push have little to do with revolutionary class objectives. Resistance in the labour process is, therefore, little more than workers' (or the labour movements') qualification of managerial control and redesign of work. The larger Marxist-oriented discourse is characterized by two dominant trends. Analysis of the Marcuse-type is defined by pessimism about the working class's capacity to be more than the subsumed object of capitalist or bourgeois hegemony. The second variant involves analyses that are so preoccupied with the immediacy of struggle for socialism that epistemological issues are glossed over (e.g. Hobsbawm, 1984). Academic variants of the Marxist-oriented discourse acknowledge the epistemological issues in class location and consciousness, but in ways that one finds suspect (e.g. Hudson, 1989). Orthodox sociological analyses of class location, subjectivity and mobilization often suggest epistemological rigour as the basis for preferring the more Weber-oriented discourse.

Improper location of worker-subjectivity, in terms of the level of abstraction, is central to the current crisis of the discourse on consciousness. Straightening out the epistemological issues allows us to make the distinction between class and consciousness, as categories of different levels of analysis. It is within this context that we argue the substantive issues in this work.

First, as a category of a much lower level of abstraction, a discussion of consciousness must immediately engage with the existentiality of the human 
subject. Second, and following from the above, worker-consciousness, as human subjectivity, will reflect the human subject as the intersection of multiple social relations, and identities forged within specific cultural and historical experiences. Gender, race, ethnic considerations and religion are examples of such intersecting identities and relations that mediate class relations and identities. Even with the best affirmation of proletarian identities and interest, these identities mediate the language of class. Language is itself constitutive of identities and a weapon of mobilization. To treat the presence of non-class issues in worker-subjectivity as evidence of no classness is to miss the specificity of each working class's experience and affirmation of its identity.

Third, worker-consciousness is forged within the context of, and unevenly in opposition to, the pre-constituted knowledge of society, that offer ontological explanations of society and the location of different groups within that society. Non-class identities come into play in the rendering of such explanations. Therborn's (1980) concept of the alter aspects of dominant class ideologies, that attempt to 'qualify ${ }^{1}$ workers for their subordinate roles in society, approximates the author's concept of 'pre-constituted knowledge*. It is within such pre-constituted knowledge, and their experiential engagement with the world as they live it, that workers try to make sense of their world and forge their interests. Workers, even in the context of apparent non-classness, are not passive consumers of their qualification by (the significant) others.

It is in the intersection of such experiential construction of identities, preconstituted knowledge, non-class relations, and identities that specific and concrete worker-consciousness emerges. The significance of this is that the dichotomy between work and non-work, class and non-class, etc., cannot advance our understanding of worker-subjectivity beyond pure analytical distinction. Rather, we require a dialectical appreciation of the intersection of work and non-work, of the class and non-class in the understanding of worker-subjectivity. In the environment of racial segregation even the labour process is structured by such non-class hierarchy. Gender discrimination and structuration in the larger society often define the hierarchical structuration of the workplace.

\section{EPISTEMOLOGICAL ISSUES IN WORKER- CONSCIOUSNESS}

The discussion in this section is important for a few reasons. First, much of the crisis in the discussion of worker-subjectivity and class identity results from the location of that analysis on the wrong level of abstraction. Here, we agree with Bourdieu (1978, p. 7) that often the analytical movement from categories of high levels of abstraction (or what he calls 'theoretical class') to specific manifestations in real life ('real class') is undertaken as if this movement is unproblematic. It is as though, consciousness, conceived in ideal-type format, is a category of the same level of abstraction as the real situations to which it is being applied. Second, the use of the 'abstract' and 'concrete', in works that emphasize theoretical rigour, begins as if the distinction is dichotomous, rather than one of levels of abstraction (hence 


\section{Annals of the Social Science Council of Nigeria, No.5, 1993}

different points of a continuum). Hence, what is better seen as a continuum takes oo an identity of duality. Emphasizing the proper location of the discussion of workerconsciousness is an important first step in overcoming the current problem.

\section{Methods of Abstraction}

In this paper, we will outline two major methods of abstraction in the philosophical discussion of the method of knowing (or theory) that are prevalent in social sciences. These are: Marx's method of abstraction, the method that characterizes the works of Max Weber and Marginalist (or neo-classical) economics. There are two main aspects to Marx's method. One is philosophical in origin, and the other is methodological. The philosophical aspect is defined by the distinction between the knowing subject and the object of his/her enquiry. As Marx (1973, pp. 101-2) points out:

The totality as it appears in the head, as a totality of thoughts, is a product of a thinking head, which appropriates the world in the only way it can... The real subject, retains its autonomous existence outside the head just as before... Hence, in the theoretical method... subject, society, must always be kept in mind as the pre-supposition.

In other words, we must 'recognize the necessary difference between the real objects of thought and the concepts' that are aspects of the real world appropriated in thought (Fine, 1982, pp. 12-13; Clarke, 1977,1982).

The second aspect of this method of abstraction (the methodological) concerns the procedure of appropriating the empirical foundations of the vocation of theorizing. To paraphrase Marx, we cannot just walk into an unfolding social relations or phenomenon and make sense of relations unfolding in front of us. A method of inquiry 'has to appropriate the material in detail, to analyze its different forms of development and to track down its inner connection. Only after this work has been done can the real movement be appropriately presented' (Marx, 1976, p. 101: emphasis mine). This is the process of 'discovering the rational kernel within the mystical shell' (Marx, 1976, p. 103). This process of abstraction involves two inter-connected aspects; one is referred to as 'levels of abstraction'. ${ }^{4}$ The other is what Diane Elson (1979, pp. 142-44) calls the procedure of 'one-sided abstraction'.

The level of abstraction, the tracking down of the inner connection involves 'starting from the complexity of the superficial world' (Fine \& Harris, 1979, p. 6), or the 'chaotic conception of the whole' (Marx, 1973, p. 100). From this stage, one moves into the inner connections until one arrives at 'the simplest determinations' of the process being investigated (Marx, 1973, p. 100). Concepts developed to describe these connections are 'the most simple, highly abstract concepts' (Fine \& Harris, 1979, p. 6; Marx, 1973, pp. 100-102; Conceptually, one has to retrace one's steps until one arrives again at the starting point. This time,' Marx points out, the conceptual appropriation is 
'not as a chaotic conception of the whole, but as a rich totality of many determinations and relations'. As we move down the levels of abstraction and embrace the increasingly more complex nature of the issue being investigated we develop 'increasingly more complex concepts... until the complexity of the world of appearances is reproduced in thought or on the page' (Fine \& Harris, 1979, p. 7).

Let me illustrate the discussion above. Imagine a football stadium with the full grip of a crucial league match. Imagine further a visitor from planet Mars, totally unfamiliar with the ways of the humanoids, finding himself/herself in the stadium. What we call a football match will be an incomprehensible mass of movements and noise, to our Martian visitor. If he/she makes sense of any or it, it must look like a complex, chaotic whole in full bloom. Making sense of the football match requires taking a mental distance from the chaotic complexity of the initial encounter, to a dismembering of the movements and noise. Our visitor must abstract away the spectacle of the fans bellowing their lungs out (ostensibly 'cheering' their teams), of humanoids chasing a spherical-shaped piece of leather in the middle of the stadium; etc. It is a mental distancing to allow an understanding of the linkages between the sets of actors and their behaviour, until the very essence of the phenomenon becomes clear. Concepts like referee, goal-keeper, fans, etc. are developed in the process. Making sense of the match and game compels our Martian visitor to mentally retrace his/her steps until he/she arrives back at the starting point Then, what initially looked like a complex chaotic whole, of incomprehensible humanoids, reveals itself, not as chaos but an outstanding match of the league season; as a rich totality.

Concepts such as mode of production capital, circuit of capital, are categories adopted in teasing out, and emphasizing the specificity of capitalism. As concepts of high levels of abstraction, they are independent of the specific manifestation of real and historically given capitalism. But they we concepts derived from real capitalism. As Marx (1973, p. 3105) notes, 'even the most abstract categories', are 'in the specific character of this abstraction, themselves... product(s) of historical relations, and possess their full validity only for and within these relations' (emphasis mine).

By contrast, the concept of the capitalist social formation (CSF), for instance, attempts to capture specific and historically given situation. While a category of abstraction, CSF is that of a very low level of abstraction reflecting highly complex interplay of many 'determinations and relations'. The relationship between categories of the highest and the lower levels of abstraction, is not that the latter replaces the former. Since they are categories of different levels, the categories of the higher levels are 'reproduced... by the more complex concepts' (Fine, 1982, p. 13). This must be separated from speculative abstraction (Clarke, 1977, p. 11; Fine \& Harris, 1979, p. 7; Fine, 1982, p. 13).

The other aspect of this method of abstraction is what Elson calls 'one-sided abstraction', which Marx continually emphasized in Grundrisse and the three volumes of Capital. In dealing with an object of inquiry, we can break the object into its constituent parts and investigate the different aspects. This stage, Elson (1979, p. 142) refers to as the 'phase of 


\section{Annals of the Social Science Council of Nigeria, No.5,1993}

individuation'. However, after this phase of the 'dissection of the tendencies or aspects counterpoised in (a historical process), comes the phase of synthesis, of reconstitution of the appearances of the form, and of re-immersing it is process' (emphases mine). The phase of synthesis does not simply recompose analysis but takes us beyond it, helping 'to correct the one-sidedness intrinsic to the first phase'. One should emphasize the unity of these two aspects of the method of abstraction. The dialectical context of this method contrasts with the procedure of dependent and independent variables that is prevalent in the social sciences.

\section{Speculative Abstraction}

Across disciplines in the Social Sciences, Economics to Industrial Relations, the idea of abstraction is -at the root of much conceptual disputation and elaboration. ${ }^{5}$ But what is this 'abstraction' and how does it differ from that discussed above? In orthodox Sociology, Weber provides the starting point Abstraction for him:

involves first the production of... 'imaginary constructs' by the disregarding of one or more of those elements of 'reality* which are actually present, and by the mental construction of a course of events, which is altered through modification of one or more 'conditions' (1949, p. 173, emphases mine; $c f$. Huff, 1984, P-15).

It is important to emphasize that unlike Marx, for Weber and the range of orthodox social science, abstraction starts in the head of the researcher. The critical element in Weber's abstraction is what is referred to as Ideal-types. As Huff (1984, p. 8) points out, Weber's abstraction is a product of an agnostic approach to reality. As Clarke (1982, p. 201) shows, "for Weber... the ideal-type had no reality of its own, it was strictly a 'Utopia', a heuristic device". Hirst (1976) has also shown that Weber's epistemology is essentially arbitrary, irrational and relativist: arbitrary in the unexplained prioritization of particularistic value-system not subject to disputation or even analytical probing. All value-systems are made equivalent while 'the choice of values is subject to no limits' (p. 64, $c f$. Weber, 1949,1969). The arbitrary and irrational essence of Weber's abstraction is most explicit in the ideal-type construct. While a product of subjectivist and arbitrary appropriation of real social processes, ideal-types as analytical devices - for apparently scientific sociological analysis - are not in themselves subject to examination. Where there is a discrepancy between the ideal-type category or model and reality, reality is deemed aberrant. This is as much a defining characteristic of Marginalist Economics as it is of Weber's Sociology.

The concept of market in Marginalist Economics, for instance, begins with a set of assumptions that are products of idea-type abstractions of the economist, rather than the real world: the size and motivation of economic actors, the free movement of resources, information, etc. Real economic institutions and systems are, however, Judged on the basis of a set of 
assumptions that are themselves not, strictly speaking, derived from real processes, but the theorists adventure in logical abstraction. Where there it sufficiently sharp diversion between thought and reality, the latter is assumed to be 'out of joint'. The idea of rationality, that is so fundamental to Weber's exhortation of capitalism and bureaucratic organizations, is more the product of the theoretician's imagination than empirically derived, in the strict sense of it. Yet, the normative hierarchy inherent in Weber's three types of leadership or organization flows from such speculative ventures.

To reformulate the theoretical foundation of Industrial Relations, Heneman (1969, p. 6) drew a distinction between Conceptual Systems and Operational Systems; the latter 'are found in real life', the former are 'logical abstractions'. As with Weber's ideal-types, they are mental constructs with theory serving as the link between reality and abstract categories or systems. It is the same distinction that Merton (1968, Ch. 2) made when arguing for the vocation of Middle-Range theories.

One should reiterate the distinction between logical or speculative abstraction and Marx's method of abstraction. The latter starts in real social processes, and has validity only for those real situations. As Clarke (1982) and Fine (1982), among others, point out, the effect of speculative abstraction is that the ideology of the dominant bloc is presented as science. For instance, the concept of rationality in Weber's Sociology is such that 'in its fullest development, it is characteristic only of a capitalist society ${ }^{1}$ (Clarke, 1982, p. 208). Marginalist Economics like orthodox Sociology, starts from a perspective that denies the historical specificity of capitalism, reduces production to purely technical process and eternalizes the capitalist society.

What has all this to do with worker-consciousness? First, in specifying the analytical procedure in Marx's method of abstraction, we can situate the various discourses on worker-consciousness. Our objection is that consciousness is treated like an ideal-type concept against which real worker-subjectivity is measured. The more adequate procedure should be to return to the starting point by re-immersing the categories of higher levels of abstraction, in the complexity of the real world; of multiple mediation. Second, that rather than the dualistic abstract/concrete division, what is involved is a continuum of abstraction from the complexity and multiple mediation, and a re-immersion of our analysis in such a multiple interpellation. Third, as we will elaborate in a moment, we ought to treat the categories of class and consciousness differently. While class can be treated as a category of the highest level of abstraction consciousness, as human subjectivity, cannot. The latter is immediately bound up in multiple 'determination', relations and identities. The problem is that many contributors to the area impute a form of consciousness, where it ought to be derived, and the language of class is mistaken for consciousness.

\section{CLASS, IDENTITY AND CONSCIOUSNESS}

Class and Class Location

A discussion of worker-consciousness must first confront the issue of class 


\section{Annals of the Social Science Council of Nigeria, No.5, 1993}

location. Class specification in the context of the analysis of capitalism-in-general (i.e., the Capitalist Mode of Production [CMP] can go on by dealing with class at the level of the simplest 'determination'). At this level of analysis, the working-class can be identified by (i) the non-ownership of means of production, and (ii) dependence on the exchangevalue of its labour-power for subsistence. This idea of the class is irrespective of the historically specific society in which a working class exists. The idea of various stages in the circuit of capital, however, allows us to anticipate segments of this class outside the sphere of production. In other words, we expect to find segments of the working class in the context of money capital or commercial capital.

At a slightly lower level of abstraction, we can incorporate Carchedi's demarcation of the functions performed in the labour process: the functions of the collective worker and the global functions of capital. This .allows us \& view of multiple classes and the ambiguous location of classes where the performance of these functions is unevenly mixed. In other words, we can expect a situation where groups of people are performing the functions of the collective worker and the global functions of capital, hi different mix. This analysis continues at this stage abstracting away strictly non-production forms of social life. The class is, at this level of the analysis, without gender, race, religion, etc.

Making sense of the idea of the working class, at the level of the analysis of social formations, of very low levels of abstraction, involves incorporating the many 'determinations' (we prefer 'mediation'), relations and identities, Across societies, gender structuration is not just adjunct to class; class is gendered. In [capitalist] social formations that have spatial cohabitation of races, race is not adjunct to class; class is usually racially structured. We can extend the same analysis to caste, ethnic or religious segmentation in which non- or pre-capitalist identities and relations are the bases on which various classes are structured. The primary relation of exploitation in the CMP is articulated and reinforced by infra-class jostling for privileges based on soared identity with the dominant class (or social bloc). ${ }^{6}$ While we will return to this in a moment, the analytical procedure raises two issues that can be pursued here. One is epistemological and the other of a specific attempt at specifying classes.

In his critique of Habermas' twin use of 'Labour and Interaction' Giddens (1982, p. 109), raised the issue of epistemological differences between Weber and Marx He correctly drew a distinction between Weber's 'purposive-rational action' and Valuerational action' as ideal-type concepts, and Marx's concepts of forces and relations of production, which are not. Incorrectly, however, Giddens read Weber's categories as analytical whereas Marx's are not. Although, this is a small point of Gidden's specific critique, such confusion is prevalent in orthodox analyses of class location and consciousness. Many Marxist-oriented writings on worker-consciousness suffer from a collapsing of ideal-type consciousness with the 'operational' forms. The concept of the 'abstract', relative to the 'concrete', is apparently drawn from Marx's paradigm, but his method of theory underscoring the paradigm is hardly followed through. 
Rather 'concrete' and 'abstract' are articulated within the epistemology of logical or speculative abstraction. The abstract becomes the ideal-type vis-a-vis the concrete phenomenon that is being analyzed. Such analysis then migrates back into what is assumed to be Marxist scholarship, without much appreciation of the profound eclecticism that result in the process of such theoretical 'cross breeding'.

In a specific case of class analysis, Bourdieu (1987, p. 7) argued that "by equating constructed classes which only exist as such on paper, with real classes constituted in the form of mobilized groups possessing absolute and relational self-consciousness, the Marxist tradition confuses the things of logic with the logic of things". In place of this, Bourdieu developed a concept of social space based on his three co-ordinates of "global volume of capital, composition of capital, and social trajectories". Bourdieu argues that classes, as they exist, interact and operate in real life, are functions of these co-ordinates. The capital in Bourdieu refers to economic, cultural, social and symbolic resources available to the individual rather than capital; in the sense of circuit of capital. Bourdieu is probably right about much of Marxist-oriented writings, in the sense that they do not constitute a 'tradition, as such. The problem with Bourdieu's analysis is that he combined different levels of analysis. Unable to find empirical use for class (a category of high level of abstraction), he went on to abandon the idea altogether. It is here that we see the link between Giddens and Bourdieu: the confusion over the epistemological foundations of Marx's method of abstraction.

Surely class in Marx's Capital has a different analytical objective compared with class as Marx used it in Eighteenth Brumaire or Class Struggle in France. In the context of Capital, Marx's objective was an analysis of capitalism in its 'pure' form. In other words, class features in this analysis as a category of very high level of abstraction. The analysis of the movements of capital and the class context is conducted by abstracting away the multiple interpellations of non-capitalist modes of production and reproduction of social life. The Eighteenth Brumaire and doss Struggle in France are works of concrete analysis of unfolding social history with all the 'chaotic' interplay of classes, groups, economic and social relations, etc. These works operate at low levels of abstraction involving the simultaneous grasping of different aspects of a social formation: different modes of, and relations of, production. Class, as used in these works, refers to and is descriptive of real social relations and struggles; very concretely so.

In the concrete discourse of the place of non-class identities and relations in the structuring of class and human subjectivity, we can take the nature and organization of work as our starting point.

\section{Primordial Identity, Class and the Labour Process}

The idea of the 'primordial' remains controversial, given its many uses. Primordial is used in this paper, in the sense of the aspects of human society and nature that are primeval (not primitive!). One is born black, white, brown, etc.; male or female. Race, ethnic origin and sex are primeval in this sense. Racialism, ethnicity and gender are, however, not primordial; in the 
sense of being primeval. Racial, sex or ethnic differences, by themselves, do not create antagonisms or hostilities. The interaction of races, sexes and ethnic groups necessarily creates the basis for the articulation of distinct identities and the reproduction of such identities; in ways that infuse such interaction with hostility. To a lesser degree, of analytic precision, we include religion as an aspect of the primordial.

It is necessary to separate these primordial identities from class since the central thesis of this paper is that these identities are the foundations of the sub-cultures of class, and the specific nature of class in given space and time. This is what we call the territoriality of class. Making sense of class consciousness requires that we pay attention to such non-class groups and sub-cultures. Central to this paper is failure of the dominant trends in the labour process debate; Western Marxism; and the sociology of labour movement to integrate race in the analysis of class (specifically worker-) consciousness.

Class, as a category of low levels of abstraction, must re-immerse itself in real social contexts. Class is, for instance, cultural or put differently, class has culture. The culture of class is fundamentally specific and grounded in a given context of time and space. For instance, the culture of the 'aristocratic* segment of the English working-class and bourgeois class only makes sense in a specific history and context, and the ambiguous victory of English capitalism over feudalism. While this seems obvious, the primordial content of class is something that until recently, when Feminism forced itself on our collective consciousness, was on the fringe of Western Marxism. The essence of non-class identities in class is, of course, not limited to skilled workers aping Us aristocracy or a bourgeoisie 'willing to kill' for a knighthood. As we noted earlier, class is gendered, religious, and racial or ethnic; and nowhere is this more obvious than at the point of production.

If there is something that the gender-conscious discourse has forced our attention to, it is that the (capitalist) labour process is fundamentally gender-structured. Workplace privileges reflect intra-working class (defined in CMP-form) segmentation and the preponderance of male power. Again. the literature is profuse on the gender-segmentation of the labour process. Studies on the experience of work in the United States of America, colonial Africa, and South Africa point to the significance of race in the structuring of the labour process. Quite often, racialism so dominates relations at the point of production that a white person never works, on the same level as, or is supervised by, a non-white person. In the context of such rigidly racialized work relations, class cannot function, even minimally, as a category of low levels of abstraction or in the consideration of worker-subjectivity, without an Acknowledgement of race. The very air that people breathe, so to say, is saturated with such primordial identities. Class action and subjectivity have resonance for those who experience such dual domination of capital and race, only when the idea of class incorporates an acknowledgement of race or gender. Analytically, class exploitation is made meaningful by gender, race, caste or religious domination.

Contrary to Hudson's (1989) argument, an analysis of class relations and identity must incorporate such primordial dimensions of class. 
Analytically, the division cannot be between 'concrete' and the 'real-concrete', since every appropriation of the real-world-thought involves some degree of abstraction. Where the primordial is at the heart of class structuration, it is part of class. In other words, the pattern of privilege and subordination has primordial resonance, and are necessary for sketching the boundaries of class itself. Carchedi's dual function in the labour-process allows us to grasp aspects of these boundaries even at higher levels of abstraction.

The more prevalent experience of the primordial in the labour process may, however, not involve such depth of racial or gender segmentation. Rather than a man never working under a woman or a white person under a non-white, the inscription of primordial segmentation into work may be more nuanced. It could be in form of the predominance of women or non-white persons in low-pay and hazardous jobs, or the significance of race or gender in having access to certain privileged jobs. Again, intraclass segmentation follows privileges and domination that derive from primordial identity. Charles Denby's autobiographical account of work experience in the US autoindustry (Indignant Heart, 1979), is recommended reading. Again, we can, analytically, hardly make sense of class without acknowledging the immediacy of the primordial. It is in the discussion of subjectivity that this becomes more obvious.

It would seem that the linkages between work and non-work are such that we cannot separate the two in our attempt to grapple with worker-identity and consciousness. Elsewhere, we have shown the extent to which workplace relations blunted the assumed dominance of ethnicity in Nigeria (Adesina, 1989, 1990), although we emphasized the problems involved in neglecting extra-workplace processes and social relations. The everyday language of the labour process and labour relations is saturated with idioms, thought processes, and value-systems that have their roots in the indigenous ethnocultural relations. This is no more peculiar than the englishness of the English working class. It seems that the dominance of primordial identities in the labour process is a function of the primacy of primordial identities in the larger society. It is considerably easier to overcome primordial segmentation in the labour process when its impact or resonance in the larger society is weak in terms of institutionalized privileges and subordination.

The discussion thus far raises questions of subjectivity and the pre-work constitution of workers as wage earners, and it is to a discussion of these that we now turn.

\section{PRE-CONSTITUTED KNOWLEDGE AND WORKER-SUBJECTIVITY}

If the movement from class, as a category of high level of abstraction, to class in real social context is problematic, the movement from class as such to subjectivity is even more so. One thing is, however, plain; the working class is not constituted in the labour process. While class location starts from the relations of production, the cultural constitution of class is in the civil society. In an environment of highly segmented primordial identities, the 
'alter-ideology of the dominating subject' (Therborn, 1980, p. 28) attempts to constitute the dominated subject in subordinate roles, and to strip away the bases of group and individual self-assertion, that may enhance resistance to the dominating subject.

For instance, female workers are often gender-oriented into subordinate roles and expectations before entering the labour market, as are black workers (or other groups) that experience institutionalized discrimination. The capitalist social formation incorporates, if unevenly, pre-or non-capitalist structures of subordination. The social processes so incorporated do not necessarily fall along class lines; it may involve patriarchal or racial privileges benefiting men and dominant race or caste. In addition, a central aspect of this preconstitution of 'reality ${ }^{1}$ is that capitalist alter-ideology mobilizes a range of normative and moral regulative mechanisms that are supportive of its dominance. The normative and moral regulations (Mahnkopf, 1986) are often sourced from non- or pre-capitalist patterns of social relations (Adesina, 1989). These are processes of the civil society; a concept that has its resonance in the idea of a capitalist social formation.

The capitalist labour process incorporates this normative and moral regulative mechanism, while reconstituting them at the point of production. Our argument is that a fragmented understanding of work and non-work process of hegemonic domination, beyond the procedure of one-sided abstraction, is futile. Elsewhere, we noted that the re-articulation of such alter-ideologies, at the point of production, and the everyday language of the labour process are saturated with pre-capitalist morality (Adesina, 1989).

The normative regulations and the explanations offered by the dominating subject have their impact in a dual way. First, they converge with the worker's experience of reality, however minimally so. But the worker's experience of reality is mediated by the preconstitution of that reality by the dominating subject. Second, the mediation of worker's experience of reality^ by a-priori explanations of the dominating subject, seems to be a function of how far the reality, being experienced, is outside the range of the worker's comprehension. In the specific case reported in Adesina (1989), the link between illness and pollution, while sensed by the workers, did not lend itself to experimental explanation. The exogenously imposed explanations (by the factory management and health arid safety specialists), are themselves discursively implanted in the head of the dominated subject through a twin legitimation process: they are products of the 'significant', if not superior, others, therefore the explanations are true. Since the 'significant' other is deemed to be more knowledgeable than the dominated subject, the former's propositions are all the more true.

The second element of the legitimation process functions in the repetitive insistence of the propositions of the dominating subject. The very repetitiveness of their affirmation, it would seem, confirms their validity! The whole framework of formal education - from preprimary to the university -affirms the knowing capacity of the dominating subject. Louis Althusser's concept of 'ideological state apparatus' was to explain how the ideology of the dominant subject saturates the very fabric of society, even if the concept is 
flawed in its state-centric discourse and structuralist analysis. Gramsci's concept of hegemony and greater sensitivity to contradictory social processes provide us with some robust explanation of the same phenomenon.

The power of mediation of the worker's subjectivity is not only in structuring the experience of the worker, but in the ways they subvert the confidence of the worker in what his or her intuition suggests. While you may object to hierarchical domination, or the world that is dominated by patriarchy, the rich and the powerful, or the racially different others; the crystallization of such objection may be undermined by the idea that patriarchy, hierarchy, etc., have always been here and will continue to be. If so, then the dominating subject's explanations of hierarchy by resorting to celestial explanation or reference to the unequal length of the fingers, for instance, would seem to confirm their truth. Such ideological constitution of the experience of work, for instance, is more the product of the civil society than of the labour process - even when they are reconstituted and sharpened in the workplace. Such alter-ideologies draw on varied sources; many from cultural antecedents of the capitalist mode of production.

So far, we have suspended an analysis of the counter-culture of the subordinate subjects that sets the limit of the hegemonic project and alter-ideology of the dominating subject. The mediation of workers' experience of life, by the pre-constitution of reality by the dominating subject cannot be taken for granted. The limit of the hegemonic project of the dominating subject is set by the worker's experience of empirical reality. The contradictions between the real world and the dominating subject's explanations, and the excruciating authoritarianism of the labour process, combine to underwrite the [experiential] subversion of the hegemonic project of the functionaries of capital. The subversion of the hegemonic project of the dominant subject is, again, not strictly a product of the labour process. The counter-culture of the dominated subject has its historicity. The segmentation of social life that is inherent in the capitalist social formation (like all segmentary social formations) fosters the construction of identities, ethos and cultural praxis, that even when heavily penetrated by the alter-ideology of the dominating subject confers a distinctness to the dominated subjects.

\section{IDENTITY, CONSCIOUSNESS AND THE LANGUAGE OF CLASS}

However subordinate, the dominated subject is also a knowing being. Class and group folklore emerge, straining to give meaning to the contradictions of lived experience, and invert the meaningfulness of the dominating subject's alter-ideology. Anthropologists are not unfamiliar with the counter-explanations that dominated subjects give the world they share with the dominating subject. Urban and workplace 'anthropologists' will also confirm similar folklore of the shopfloor. In Adesina (1990), the author argued that the construction of social communities in work flows from shared experience of the labour process. Such communities are, however, structured by collective consciousness of the urban-based subordinate bloc in the larger 


\section{Annals of the Social Science Council of Nigeria, No.5, 1993}

society. The impact of the 'Lateral Community in Work' (LCW), - for instance, is in the reconstruction of extra-workplace identities (e.g. ethnic plurality) to the point where such identities are subsumed by the proto-class collectivity. The LCW, the author argued, is underscored by a set of ethos that we called the Alternative Morality. It is a set of ethos that offers competing explanations to the alter-ideology of the functionaries of capital and state. It is a set of normative constructs that becomes the basis of the counter-culture of the shopfloor reported in Adesina (1989).

The shopfloor ethos is the cultural repository of counter-cultural practices, shopfloor revolts and union militancy, and assert the independent identity of the shopfloor workers. It is primarily rooted in experiential intercourse with reality, and is discursively asserted (Adesina 1989). The new shopfloor entrant's experience of work is mediated by these counter-cultural ethos and identities. Marcuse-type pessimism of workers crushed under the hegemonic weight of the capitalist (or the functionaries of capital and state) would be missing a lot, even when such processes are unfolding in front of the analyst (Adesina, 1989,1990).

Embryonic and tentative though they may be, the ethos embraced by the alternative morality of the shopfloor workers reflect definite class content. Yet, the language of the shopfloor is shot through with earthy reference to the ecology of the tropics. Exploitative relations find their verbalizing in the domination of monkeys by baboons: "Monkey dey work, baboon dey chop". The social practices that assert mutual support and defence are underwritten by references to ethno-cultural practices that reinforce mutual survival. As the author also noted, (Adesina, 1989), even discourses that at first, sound subservient to the management corps and the state, can easily become subversive. The moral of the story is the reflection of the class and non-class in the militant counter-culture of these shopfloor workers. The territoriality of class is reflected in the idiosyncrasies of class identities that are historically and culturally specific.

The low resonance of ethnicity among the workers in the study mentioned above may be the result of the absence of ethnically institutionalized privileges and domination. Their high assertiveness may be a result of the freedom that the process plant technology allows workers relative to the conveyor belt technology (i.e., the Fordist labour process). The high impact of racially structured privileges in the larger society will reflect in the labour process and the class. In such contexts, the primordial may acquire greater resonance than class. The resolution of one form of exploitation (value-form) required the solution of the other; racial, gender or religious. Even where race and gender may not have such a strong presence, the failure to acknowledge the potency of the primordial in intra-class privileges, alienates the subordinate segments. The degree to which workers' organizations are patriarchy-structured and exclusive of women is an issue that Feminist scholarship has compelled us to acknowledge. The experience of the labour movement in the US attests to the racial structuring of the trade union movement. Surely, the lived experience of the AfricanAmerican worker in the US or the African worker in South Africa is not just of class, but racial.

The experience of racially structured class, like gender-structured class, 


\section{Rethinking Worker-Consciousness 133}

is palpably inscribed in the subjectivity of the worker. The revolt against subordination will reflect the duality of commodity exploitation and racial or gender domination. In so far as revolt is itself discursively constructed, the impact of the primordial experience will depend on how the primordially subordinate faction of the working class sees the primordially privileged faction. It is not unlikely that the privileged faction of the working class will conduct its struggles with little or no acknowledgement of the racially and gender-dominated segments. In the case of the United States and Britain, for instance, segments of the predominantly white labour movement conducted its struggles in hostility to women, African-Americans and other segments. Of course, the constitutive language of the primordially dominated segments of the working class will militantly assert their particular experience of commodity relations.

This brings us to the final question of the linkages between consciousness and the language of class. As Stedman Jones (1983, pp. 21-22) notes:

Language disrupts any simple notion of the determination of consciousness by social being, because it is itself part of social being. We cannot, therefore, decode political language to reach a primal and material expression of interest since it is the discursive structure of political language which conceives and defines interests in the first place. What we must do is to study the production of interest, identification, grievances and aspiration within political languages themselves. We need to map [in the case of the Chartist Movement] these successive languages of radicalism, liberalism, socialism, etc., both in relation to the political languages with which they are in conflict.

The important caveat that Gray (1986, p. 367) raised is this: "If language is 'part of social being' then it must be seen, like other parts of social being, as multi-layered, complex, fractured, composed of incoherences and silences, as well as the smooth flow of would-be authoritative public discourses".

The implications are at least three-fold. First, asserting a working class consciousness that is valid only in its definitive orientation to socialism of our scholarship (or worst still of the 'dictatorship of the proletariat") and revolutionary upsurge, leads to a Big-Bang theory of consdousness (Adesina, 1989). Second, many who claim to be writing in the Lenin/Lukac tradition begin from a definition of a consciousness that is imputed to the working class, but then go on with their analysis of empirical worker-subjectivity as if their starting point was analytically derived, rather than politically imputed. Distinctions between trade union and revolutionary consciousness, which was used by Lenin to analyze aspects of a continuum, take the form of binary opposites in the writings of others. The language of class is in the process mistaken for consciousness. Also, as Luxembourg warned, "the patronizing of the proletariat by intellectual elites leads to a weakening of the ability to act, and to passivity" (Fetcher, 1985, p. 80).

Third, major sections of Western Marxism reflect the gender and racial 
locuses of the contributors. Very frequently they dismiss as non-class what they do (or will) not comprehend. ${ }^{17}$ In the same way, the revival of 'labour internationalism' that starts by abstracting away the territoriality of each working class (or segments of it) reproduces imperial relations not class-solidarity.

The language of class can function in the constitution of trans-racial and transgender identities and accentuate class constituency, but the primordial $\bullet$ till features in worker-consciousness, even when the (class- constituting) language of class subsumes it. Consciousness is only to a weaker or stronger extent class, but hardly ever, nonprimordial. Oloyede (1991, p. 47) proposed a two-fold understanding of workers' class consciousness; that is, class solidarity and the workers seeing their interests as being at woods with those of the dominating subject. We can supplement this with a suggestion that class solidarity should be gender-conscious, race- conscious, etc., (as should the discussion of class subjectivity). Furthermore, while the language of class may discursively jettison the primordial, consciousness cannot, and hardly ever does.

\section{Acknowledgements}

My gratitude to Izielen Agbon and Abubakar Momoh, for their assistance at the formative stages of this paper. I also acknowledge the contributions of the participants at the 1993 "Word, Class and Culture" Symposium, held in June at the University of Witwatersrand, Johannesburg; and the Ibadan Sociology Staff Seminar series in January 1994. Their comments have gone a long way in shaping the final product. I alone must, of course, bear the burden of remaining errors in this paper. 
Rethinking Worker-Consciousness 135

\section{ENDNOTES}

1. Elsewhere, I have highlighted the substantive advances in Burawo/s discourse on the labour process after 1979 (Adesina, 1992).

2. Frank Parkin's Marxism and Class Theory: A Bourgeois Critique (1979) and Daniel Bell's The Misreading of Ideology ${ }^{1}$ (1990) may be two polemical examples, but similar assumptions underscore Pierre Bourdieu (1987). The more sympathetic treatment by Giddens also carries the assumption of unequal espitemological rigour (1989, p. 109). Gidden's position is discussed further below (in the body of this paper).

3. In other words, lower than others such as mode of production, class or capital that can be defined regardless of the specific form of their manifestation in a given social formation.

4. $\quad C f$. Mandel (1976, pp. 29-30); Braveman (1976, p. 121); Clarke (1977, pp. 1011,1982, Ch. 4); Fine \& Harris (1975, pp. 6-8); Shaikh (1981, p. 291); and Fine (1982, pp. 12-18).

5. In Industrial Relations, for instance, one of the grounds of criticism of Dunlop (1958) by Wood et al (1975), was that Dunlop misunderstood Talcott Parson's project 'conflating the concrete and the analytical' (ibid). Dunlop (1958, p. 6) himself referred to concepts of industrial relations system and the economic system as 'logical abstraction'.

6. The literature on such segmentation, derived from non-class identities, is profuse. Specific citations need not delay us here.

7. Bourdieu's project could have qualified for analysis of very low levels of abstraction, but the problem with his argument is that we can easily move from multi-dimensionality to the situation where the various 'capital' end up as analytical equivalents. A set of 'capital' with no primacy of effectively is an analytical cop-out; an essentially Weberian discourse.

8. Writings claiming Marxist pedigree or orientation do clearly tend towards the Babel-type dissonance. A haphazard comprehension of Marx is often supplemented by eclecticism; itself a reflection of training in an environment of hostility of Marxist scholarship. $\quad C f$. Adesina (1992) for the specific case of the labour process debate, and Easthope (1988) on post-structuralism in Britain. At other times, politics imposes itself on scholarship in a way that the latter fades out entirely.

9. $\quad C f$. Oloyede (1991) on Nigeria, CSE Sex and Class Group (1982).

10. Cf. Georgakas and Surkin's Detroit: I do mind dying (1975) and the collection in Braham et al (1981), among many. Being relatively unfamiliar with literature on South Africa, I am handicapped in citing the relevant works, but I am sure my colleagues in the country are not unaware of such works. 
136 Annals of the Social Science Council of Nigeria, No.5,1993

11. By hindsight, this is an important caveat to my study of the Nigerian oil industry (cf. Adesina 1989).

12. By 'Lateral Community* in Work, I mean social collectivity or community of workers that develops within the workplace, horizontally among workers, binding them together horizontally. For a full discussion of the LCW, see (Adesina, 1989).

13. The LCW competes with other collectivities: the most significant of which is the attempt to develop a feeling of corporate citizenship and identity with the firm.

14. Translation: "Monkeys do the labouring, baboons do the eating".

15. Odafe (pseudonym), a middle-age caustic leader, once asked me: "naw be gov'ment own di refinary? Naw be gov'ment own we? So why deh treat we like dis?" (The refinery belongs to the government, doesn't it? We belong to the government, don't we? So why should they treat us so shabbily?)

16. Cf. Georgakas \& Surkin (1975), Braham et al (1981), CSE S \& CG (1982) among others.

17. The same rejection, based on non-comprehension underscores the agnostic or atheistic tendency that is imputed into Marxism, since I am not convinced that a materialist analysis succeeds in controverting the existentiality of God. Modern atheism [practical or theoretical] seems more a result of the revolt against the medieval church; its functioning as part of the mechanism of social domination, and the scienticist positivism of the 19th Century (perhaps [personal] tragedies that seem to contradict the existence of a good and benevolent God).

\section{BIBLIOGRAPHY}

I. Adesina, 1989, 'Worker-Consciousness and Shopfloor Struggles' in Labour, Capital and Society, VoL22 (November).

, 1990, The Construction of Social Communities in Work' in Capital and Class, No. 4, (Spring).

1992, 'Labour Process and Labour Relations', in D. Otobo (ed.) Labour Relations in Nigeria, Vol. 1, Lagos, Malthouse Press.

D. Bell, 1990, The Misreading of Ideology in Berkeley Journal of Sociology, Vol.35.

P. Bourdieu, 1987, 'What makes a Social Class' in Berkeley Journal of Sociology, Vol. 32.

P. Braham, 1981, Discrimination and Advantage in Employment: The Experience of Black Workers, London, Harper \& Row. 
Rethinking Worker-Consciousness 137

H. Braverman, 1974, Labour and Monopoly Capital, New York, Monthly Review Press. , 1976, Two Comments' in Monthly Review, Vol. 28, No. 3, (July-August).

M. Burawoy, 1979, Manufacturing Consent: Changes in the Labour Process under Monopoly Capitalism, Chicago: University of Chicago Press.

G. Charchedi, 1975, 'On the economic identification of the new middle class', Economy and Class, Vol. 4, No. 1.

S. Clarke, 1979 'Marxism, Sociology and Poulantzas' in Capital and Class, No. 2 (Summer). , 1982, Marx, Marginalism and Modem Sociology for Modem Sociology: from Smith to Max. Weber, London, Macmillan.

CSE Sex and Class Group, 1982, 'Sex and Class' in Capital and Class, No. 16 (Spring).

C. Deaby, 1979, Indignant Heart: Testimony of A Black American Worker, London, Pluto.

J.T. Dunlop, 1958, Industrial Relations System, London, Feffer \& Simons, Inc.

A. Easthope, 1988, British Structuralism since 1968, London, Routledge and Kegan.

D. Elson, 1979, The Value Theory of Labour' in D. Elson (ed.), Value, London, CSE Books.

I. Fetcher, 1985, 'Class Consciousness' in T. Bottomore, et al (eds), A Dictionary of Marxist Thought, Oxford, Blackwell.

B. Fine, 1982, Theories of the Capitalist Economy, London, Edward Arnold. and

L. Harris, 1979, Re-reading Capital, London, Macmillan.

D. Georgakas and M. Surkin, 1975, Detroit: I do mind dying, New York, St Martin's Press.

A. Giddens, 1982, Profiles and Critiques in Social Theory, Basingstoke, Macmillan Press.

J. Goklthorpe, et al, 1969, The Affluent Worker Industrial Attitude and Behaviour, Cambridge, Cambridge University Press.

R. Gray, 1986, 'The Deconstructing of the English working class' in Social History, Vol. 1L, No. 3, (October).

H.G. Heneman, 1969, Towards a General Conceptual System of Industrial Relations: How do we get there? in G. Somers, (ed.), Essays in Industrial Relations Theory, ISUP. P. Hirst, 1976, Social Evolution and Sociological Categories, London, George AAlkaUnwia. 
E. Hobsbawm, 1984, Worlds of Labour: Further Studies in the History of Labour, London, Weidenfeld and Nicolson.

P.A. Hudson, 1989, 'Class, Race and Subjectivity in South Africa,' 'in Labour, Capital and Society, Vol. 22, No. 2 (November).

T.E. Huff, 1984, Max Weber and the Methodology of the Social Sciences, New Brunswick, Transaction Books.

B. Mahnkopf, 1986, 'Hegemony and Consent' in Berkeley Journal of Sociology, Vol. 31.

E. Mandel, 1976, 'Introduction', in K. Marx, Capital, Vol. 1, Harmondsworth, Penguin/NLR.

K. Marx, 1976, Grundrisse, Harmondsworth, Penguin Books, New Left Review.

__, 1981, Capital, Vol. Ill, -Harmondsworth, Penguin Books, New Left Review.

R.K. Merton, 1968, Social Theory and Social Structure, New York, The Free Press.

O. Oloyede, 1991, Coping Under Recession: Workers in a Nigerian Factory, Uppsala.

F. Parkin, 1979, Marxism and Class Theory: A Bourgeois Critique, London, Tavistock.

Anwar, Shaik, 1981, 'The Poverty of Algebra', in I. Steedman et ai. The Value Controversy, London, Verson/NLB.

G. Stedman-Jones, 1983, Languages of Class: Studies in English Working Class History, 1832-1982, Cambridge, Cambridge University Press.

G. Therborn, 1980, The Ideology of Power and the Power of Ideology, London, Verso.

M. Weber, 1949, The Methodology of the Social Sciences, New York, The Free-Press. , 1969, Economy and Society (Vols.), New York, Badminister Press.

S.J. Wood, et al, 1975 "The 'Industrial Relations System' Concept as a Basis for Theory in Industrial Relations", in British Journal of Industrial Relations, Vol. XIII, No. 3 (November). 